\title{
Plasma exchange in the treatment of Guillain-Barré syndrome: experience in a sub-regional referral centre
}

\author{
N.A.B. Anderson ${ }^{1}$, T. Kyriakides ${ }^{2}$, I.T. Ferguson ${ }^{2}$ and T.B. Wallington ${ }^{1}$ \\ ${ }^{1}$ South West Regional Transfusion Centre, Southmead Road, Bristol BS10 5ND and ${ }^{2}$ Department of \\ Neurology, Southmead Hospital, Southmead, Bristol, UK
}

\begin{abstract}
Summary: Plasma exchange became popular in the treatment of Guillain-Barre syndrome with the publication in 1985 of results by the Guillain-Barré Study Group. Since then we have treated 24 patients referred for plasma exchange. We have audited their outcome and compared this with the results of patients in the treatment arm of the USA Study. Our patients were of comparable age and clinical severity and had similar duration of illness before starting plasma exchange. Nine of our patients required ventilation for a median of 24 days. The median time to improve one clinical grade was 19 days which compared well with the Study Group results. We have shown that plasma exchange may be safely performed in a district general hospital in a setting appropriate to the patient's clinical condition. We concur with the central conclusion of the Study, that if treatment is started early in the disease, the patient's outcome is improved.
\end{abstract}

\section{Introduction}

Guillain-Barré syndrome is an acute inflammatory demyelinating neuropathy whose aetiology is incompletely understood. ${ }^{1}$ The incidence has been estimated at 1.9 per $100,000 .^{2}$ Plasma exchange has been used in the treatment of this condition because of evidence of a circulating plasma factor, probably antibody toxic to peripheral nerve myelin. ${ }^{3}$ Results were initially mixed ${ }^{4,5}$ but the role of plasma exchange was established by the Guillain-Barre Syndrome Study Group in North America. ${ }^{6}$ This demonstrated a marked beneficial effect especially if plasma exchange was carried out early in the disease. In this paper we report our own experience and results in 30 patients referred for plasma exchange to a hospital which provides this service on a supra-district basis.

\section{Patients}

Grade 4 or 5 or were deteriorating. Twenty-four patients were treated and data are available on $2 \mathscr{S}$ of these. Patient details are described in Table II

Table I Clinical grading used by the Guillain-Barré Syndrome Study Group ${ }^{6}$

\begin{tabular}{ll}
\hline Grade 0 & Asymptomatic \\
Grade 1 & Minimal symptoms \\
Grade 2 & Able to walk 5 metres unaided \\
Grade 3 & Able to walk 5 metres with aid \\
Grade 4 & $\begin{array}{l}\text { Bed-bound } \\
\text { Requiring assisted ventilation for at } \\
\text { least part of the day } 5\end{array}$ \\
Grade 6 & Dead \\
\hline
\end{tabular}

Patients were drawn from a population of 1.5 million. Between January 1985 and August 1988, 30 patients with a diagnosis of Guillain-Barré syndrome were referred for consideration of plasma exchange. The patients were seen by a consultant neurologist (ITF) to confirm the diagnosis, and to grade patients clinically using the criteria of the Guillain-Barré Study Group; ${ }^{6}$ grading details are shown in Table I. Patients received plasma exchange if they were clinically

Correspondence: N.A.B. Anderson

Accepted: 24 September 1990

Table II Patient details

\begin{tabular}{lcc}
\hline & & GBS Study Group \\
& $n=21$ & $\begin{array}{c}\text { Treated patients } \\
n=122\end{array}$ \\
\hline Age (years) & $44.5 \pm 18.5$ & $44.3 \pm 19.0$ \\
Clinical grade & $4.4 \pm 0.5$ & $4.3 \pm 0.7$ \\
Days from first & $11.7 \pm 7$ & $11.3 \pm 6.5$ \\
$\quad$ symptoms to & & \\
plasma exchange & $9(41 \%)$ & $56(46 \%)$ \\
\hline
\end{tabular}

Results are expressed as mean \pm 1 s.d. Our patient details are compared with Guillain-Barré Syndrome (GBS) Study Group patients in the treatment arm of the study. *South Western Regional Transfusion Centre. 


\section{Methods}

Nineteen patients were treated with a Haemonetics H30 machine. Three patients with high haematocrits and body weights were treated with an IBM 2997 to avoid unduly long processing times. Fifteen patients were treated on the Intensive Care Unit, 9 on a general medical ward and 1 in an apheresis unit. Patients were admitted to the Intensive Care Unit if they had respiratory difficulty, cardiac or bulbar involvement. A course of 5 plasma exchanges ( $40 \mathrm{ml} / \mathrm{kg}$ body weight) over a week was planned for each patient but this was shortened if the patient's neurological condition, which was assessed daily, improved. Replacement fluid was $0.9 \%$ sodium chloride and $4.5 \%$ human albumin solution in a $1: 1$ proportion. Four patients received intravenous immunoglobulin at the end of the course of exchanges, because of intercurrent infection. Venous access was obtained via a central line (sub-clavian or femoral) in 14 and via peripheral veins in 8 patients. The number of exchanges performed is shown in Table III. A retrospective survey of the outcome of treatment was made by reviewing patients' hospital notes after discharge, and contacting patients by telephone or letter where necessary.

\section{Results}

\section{Outcome}

The outcome of treatment was assessed in terms of time taken to improve one clinical grade, days of ventilation and death. The results are shown in Table IV where they are compared with the treated patients in the Guillain-Barre Syndrome Study. They show a similar outcome.

Relapsed patients Two patients relapsed after plasma exchange. The first patient was being treated for a pulmonary embolus diagnosed by a ventilation-perfusion scan, the relapse occurring 23 days after a course of 5 exchanges. He received a further 5 exchanges and improved from clinical grade 4 to 3 in 21 days. The other patient relapsed 17 days post-exchange and also received a second course of 5 exchanges. He required ventilation for 10 days, and reached clinical grade 364 days after the relapse.

Untreated patients Five of the six untreated patients were clinical grade $2-3$ on presentation; the other was grade 4 . All were improving at the time of referral. The outcome of these patients was variable. Two recovered completely within 14 days after the onset of symptoms, and one after 44 days. Follow-up data are not available for the other 3 patients.
Table III Number of exchanges performed in 22 patients with Guillain-Barré syndrome

\begin{tabular}{cc}
\hline $\begin{array}{c}\text { Number of } \\
\text { patients }\end{array}$ & $\begin{array}{c}\text { Number of } \\
\text { exchanges performed }\end{array}$ \\
\hline 2 & 6 \\
10 & 5 \\
3 & 4 \\
5 & 3 \\
2 & 2 \\
\hline
\end{tabular}

Table IV Outcome

\begin{tabular}{lcc}
\hline & $\begin{array}{c}\text { SWRTC } \\
n=22\end{array}$ & $\begin{array}{c}\text { GBS Study Group } \\
\text { Treated patients } \\
n=122\end{array}$ \\
\hline $\begin{array}{l}\text { Days ventilated (median) } \\
\text { Days to improve one } \\
\text { clinical grade (median) }\end{array}$ & 26 & 24 \\
Number of deaths & 19 & 19 \\
\hline
\end{tabular}

Our patients are compared to patients in the treatment arm of the Guillain-Barre Study. ${ }^{6}$

\section{Complications}

Plasma exchange was performed successfully in 80 instances. One patient died of pneumonia 3 months after a course of 5 exchanges. She had repeated chest infections and did not leave hospital. One patient developed a septicaemia related to a central intravenous line which manifested as severe rigors during the course of 2 exchanges and which were initially thought to be reactions to albumin. Eleven low volume exchanges were performed when problems with venous access, poor flow rates or a technical failure caused early termination of the procedure. Other clinical problems which we consider unlikely to be directly related to plasma exchange are recorded in Table $\mathrm{V}$.

\section{Discussion}

The advent of the Guillain-Barre Syndrome Study Group report has produced a demand for plasma exchange in the treatment of this disease. Provided that the outcomes demonstrated by the Study Group are reproducible in everyday practice, this treatment is both clinically desirable and costeffective. ${ }^{7}$ In this report we have audited our own results and compared them to those reported by the Study Group. Our patients had comparable prognostic features with regard to age, time taken to deteriorate to clinical grade 4 and need for ventilation. ${ }^{8,9}$ We have shown outcomes which appear to be similar to the Study Group with comparable 
Table $\mathbf{V}$ Complications not directly attributed to plasma exchange in 22 patients with Guillain-Barré syndrome

\begin{tabular}{|c|c|}
\hline & $n(\%)$ \\
\hline Hypertension & $1(4.5)$ \\
\hline Severe cardiac arrhythmia & $1(4.5)$ \\
\hline Minor cardiac arrhythmia & $6(27.2)$ \\
\hline Infection requiring antibiotics & $10(45.5)$ \\
\hline Pulmonary embolus & $1(4.5)$ \\
\hline Hyponatraemia $\left(\mathrm{Na}^{+}<130 \mathrm{mmol} / \mathrm{l}\right)$ & $5(22.7)$ \\
\hline Unexplained drop in haemoglobin $>3 \mathrm{~g} / \mathrm{dl}$ & $6(27.2)$ \\
\hline Labile blood pressure & $4(18.0)$ \\
\hline
\end{tabular}

complication and relapse rates and few problems directly attributable to the procedure.

Hyponatraemia was not reported by the USA study but has been described as a complication of

\section{References}

1. Ashbury, A.K., Arnason, B.G., Karp, H.R. \& McFarlin, D.E. Criteria for diagnosis of Guillain-Barré Syndrome. Ann Neurol 1978, 3: 565-566.

2. Kennedy, R.H., Danielson, M.A., Mulder, D.W. \& Kurland, L.T. Guillain-Barré syndrome: a 42 year epidemiological and clinical study. Mayo Clin Proc 1978, 53: 93-99.

3. Koski, C.L., Humphrey, R. \& Shin, M.L. Anti-peripheral myelin antibodies in patients with demyelinating neuropathy: quantitative and kinetic determination and serum antibodies by complement component 1 fixation. Proc Natl Acad Sci USA 1985, 82: 905-909.

4. Greenwood, R.J., Hughes, R.A.C., Bowden, A.N. et al. Controlled trial of plasma exchange in acute inflammatory polyradiculoneuropathy. Lancet 1984, i: 877-879.

5. Osterman, P.G., Lundemo, G., Pirskanen, R. et al. Beneficial effects of plasma exchange in acute inflammatory polyradiculoneuropathy. Lancet 1984, ii: 1296-1299.
Guillain-Barré syndrome. ${ }^{10}$ Poor blood flow rates through venous cannulae associated with clinical dehydration were common early in the course of treatment, and we have also found patients with initial high haemoglobin levels which fell during the course of treatment without apparent blood loss. We postulate that both of these problems may be the result of initial haemoconcentration which was corrected during the hospital treatment. Plasma exchange can be safely performed in a district general hospital in the clinical setting appropriate to the patient's condition, either a general medical ward or intensive care unit. We would emphasize the central conclusion of the Guillain-Barré Syndrome Study Group: that patients who are clinical grade 3 or worse or who are deteriorating should be offered plasma exchange. This should be started as early as possible in the disease.

6. The Guillain-Barré Syndrome Study Group. Plasmapheresis and acute Guillain-Barré Syndrome. Neurology 1985, 35: 1096-1104.

7. Editorial. Plasma exchange for neurological disorders. Lancet 1986, ii: $1313-1314$.

8. McKhann, G.M., Griffin, J.W., Cornblath, D.R., Mellits, E.D., Fischer, R.S., Quaskey, S.A. and the Guillain-Barré Study Group. Plasmapheresis and Guillain-Barré syndrome: analysis of prognostic factors and the effect of plasmapheresis. Ann Neurol 1988, 23: 347-353.

9. Winer, J.B., Hughes, R.A.C. \& Osmond, C. A prospective study of acute idiopathic neuropathy I. Clinical features and their prospective value. J Neurol Neurosurg Psychiatry 1988, 51: 605-612.

10. Posner, J.B., Ertel, N.H., Koseman, R.J. \& Scheinberg, L.C. Hyponatraemia in acute polyneuropathy. Arch Neurol 1967, 17: $530-541$. 